\title{
RITUAL E XAMANISMO ENTRE OS KAINGANG: 0 TEMPO E A SOCIOCOSMOLOGIA DOS ESPAÇOS RITUAIS ${ }^{1}$
}

ALEXANDRE AQUINO2

UFRGS

RESUMO: A conexão espaço-tempo é interpretada a partir de dados etnográficos e de análise de (espaços) rituais que indicam formas de relação social entre os Kaingang fundadas na reciprocidade de kamë e kanhru krë, as metades patrilineares e exogâmicas. Essa reciprocidade é constantemente afirmada no contexto intra e interaldeão por meio de regras de etiqueta e arranjos institucionais que envolvem, principalmente, o parentesco, o xamanismo e a liderança. De fato, os Kaingang relacionam-se entre si e com os Outros, que compõem seu cosmos, a partir da interação entre os que pertencem a uma ou outra metade, dos kujá (xamã) $e$ dos pa $i$ (cacique), que se articulam, nesse caso, para fundar aldeias na região litorânea.

PALAVRAS-CHAVE: Xamanismo; Liderança; Constituição de aldeias.

ABSTRACT: The connection space-time is interpreted according to ethnological data and rituals (spaces) analysis which indicate forms of social relation between Kaingang founded in the reciprocity of kamë and kanhru krë, patrilinearity and exogamic moieties. This reciprocity is constantly affirmed in the contexts intra and inter village through etiquette rules and institutional arrangement which involve, mainly, kinship, shamanism and leadership. In fact, Kaingang have relationships among themselves and with Others, who compose their cosmos, based on the interaction between those who belong to this or that moiety, kujá (xamã) and pa i's (cacique) who articulate themselves, in this case, to found villages in the coastal area.

KEYWORDS: Shamanism; Leadership; Villages' constitution.

\footnotetext{
${ }^{1}$ Uma primeira versão deste artigo foi apresentada na X Reunião de Antropologia do Mercosul, realizada na Universidade Nacional de Córdoba, Argentina, entre 10 e 13 de julho de 2013. GT 66 -Rituales: transformaciones cosmológicas y socio-históricas.

${ }^{2}$ Possui graduação em Ciências Sociais pela Universidade Federal do Rio Grande do Sul (UFRGS, 2005). Fez mestrado em Antropologia pela Universidade de Brasília (2008) e é doutorando em Antropologia Social (PPGAS-UFRGS). Participa como pesquisador associado do Núcleo de Antropologia das Sociedades Indígenas e Tradicionais - NIT/UFRGS desde o ano de 2002. E-mail: antropoaquino@gmail.com.
}

Espaço Ameríndio, Porto Alegre, v. 8, n. 1, p. 109-134, jan./jun. 2014. 


\section{Apresentação}

Várias etnografias informam que umas das características mais importantes nas relações intra-aldeã e entre aldeias kaingang 3 são as mediações do pa i (cacique) e do kujá (xamã), as quais lhes permitem atuar para benefício do seu povo. Como veremos, para fundar aldeias na região litorânea ${ }^{4}$, os Kaingang enfatizam que pa i tar há (a "boa força do cacique") e kujá tar há (a "boa força do xamã") são atitudes idealmente complementares, já que a partir de suas respectivas capacidades motivam as ações das pessoas da comunidade para o kanhgág há kar (o "bem-viver") e o kanhgág jykre (o "bom-pensamento").

De fato, como argumento nesse artigo, por meio da descrição do II, III e IV Encontro dos kujá, realizados na aldeia Morro do Osso, município de Porto Alegre, respectivamente em 2007, 2010 e 2012, e da análise da configuração de espaços rituais, as alianças intra e interaldeias são realizadas por meio de regras de etiqueta e arranjos institucionais relacionados aos gêmeos ancestrais, kamë e kanhru, a partir dos quais os discursos e as atuações do pa'i e do kujá estabelecem uma lógica de continuidade entre o tempo mítico (gufã), o tempo antigo (vãsy) e o tempo atual (ürı), com o intuito de estabelecer

\footnotetext{
${ }^{3}$ Os Kaingang pertencem à família linguística Jê, constituindo seu idioma, juntamente com o dos Xokléng, o grupo Jê-meridional. Atualmente, os Kaingang vivem em aldeias localizadas nos seguintes estados brasileiros: Rio Grande do Sul, Santa Catarina, Paraná e São Paulo. Utilizo a forma Kaingang para designar o povo ou etnia, segundo designação convencional pela qual se tornou conhecido dentro e fora da antropologia. Esta designação deriva da palavra kanhgág, que significaria "gente", "pessoa", e "índio" kaingang (VEIGA, 1994; COELHO DE SOUZA, 2002). Os Kaingang dizem: "kaingang [pronunciando como se lê] foi o branco que botou, o certo é kanhgág".

${ }^{4}$ A territorialidade kaingang é comumente associada ao Planalto Meridional, apesar de existirem referências arqueológicas, históricas e linguísticas de ocupação da região litorânea por essa etnia, segundo Tommasino, "pode-se evidenciar a possibilidade da presença Kaingang na região litorânea. Além destas evidências colocadas por Von Ihering, há outros indícios relevantes na língua desse povo (...) Por outro lado, Borba no seu vocabulário arrola também a palavra rãnhrãinha como sendo 'areia, praia e costa' (...). A nossa pesquisa também levantou informação nesse sentido: os Coroados Bravos do rio Laranjinha que foram contatados em 1930 contaram aos membros da expedição dos SPI que seus ancestrais teriam vindo de goj-kafã-tü. Estes dados remetem, portanto, para a possibilidade dos Kaingang terem vivido mais próximos do litoral, o que torna plausível que a serra mítica Crijijimbé refere-se mesmo a Serra do Mar, como afirma Borba" (TOMMASINO, 1995, p. 44). Realizei, recentemente, estudos de Fundamentação Antropológica no âmbito do convênio FUNAI-UNESCO, que são mais aprofundados e trazem dados históricos relevantes para a ocupação do litoral do Rio Grande do Sul pelos Kaingang, os quais ainda não estão disponíveis para o público em geral. A análise, aqui, sobre a fundação de aldeias nessa região, restringe-se aos aspectos cosmológicos, organização social e política, tradição oral, desde que foram subtraídas fontes documentais.
}

Espaço Ameríndio, Porto Alegre, v. 8, n. 1, p. 109-134, jan./jun. 2014. 
um aglomerado político-cerimonial e fundar uma aldeia neste sítio considerado ancestral.

\section{A relação entre aldeias na região litorânea: o Encontro dos kujá e a fundação da aldeia Morro do Osso}

Como mostrei na dissertação de mestrado (AQUINO, 2008), a constituição de aldeias na região litorânea do Rio Grande do Sul obedece à mesma lógica encontrada na relação entre aldeias-satélites e aldeiamãe, observada no Planalto Meridional (onde se encontram as "terras tradicionais" demarcadas dos Kaingang). Como sabemos, tal argumento encontra respaldo em modelos arqueológicos ${ }^{5}$, além de conciliar etnografias contemporâneas com pesquisas históricas, as quais informam que um conjunto de aldeias, isto é, vários grupos locais relacionados entre $\mathrm{si}$, compõe os limites espaciais de uma Terra Indígena Kaingang, formando uma "unidade sociopolítica" (TOMMASINO, 1995), uma "unidade político-territorial" (FERNANDES, 2004), um "conjunto da comunidade", vï jamã [ëmã] kaingang (SCHWINGEL, 2001), um "aglomerado interaldeão" (AQUINO, 2008).

Ali, verifiquei que as aldeias dessa região se inscrevem em uma lógica de relações sociais, políticas e cerimoniais específicas, em que permanecem as características que marcam o lugar de uma aldeia-mãe, ou seja, aquelas que fundamentam a constituição de certas aldeias como centros cerimoniais, com especialistas rituais, e centros políticos, com chefia, ocupada em resolver "as coisas de fora". Mais especificamente, descrevi eventos e práticas sociais em que percebi que as aldeias de São Leopoldo, Lajeado, Farroupilha, Lomba do Pinheiro e Estrela - enquanto aldeias-satélites - tendiam a submeter-se à Aldeia Morro do Osso - enquanto aldeia-mãe, configurando uma

\footnotetext{
${ }^{5}$ Podemos visualizar por meio da análise de Dias (2004) algumas relações entre os sítios arqueológicos da Tradição Taquara e a ocupação kaingang na encosta da serra e no litoral do Rio Grande do Sul - o que o autor denomina de "áreas adjacentes" ao planalto -, possivelmente correspondente às fases Taquara (planalto), Guatambu na (encosta da Serra) e Taquaruçu (litoral). Neste caso, o território ocupado pelos Kaingang, que se estendia do planalto ao litoral, por meio de "grupos e subgrupos", até o século XIX, fragmentou-se com o avanço da colonização, de tal modo que houve redução territorial e degradação ecológica do seu habitat, configurando uma situação histórica em que sua interiorização para o planalto ameaça diretamente a sobrevivência física e cultural.
} 
territorialidade ainda flexível, certamente, pois essas aldeias em constituição se encontravam em processo de reivindicação e/ou com características comuns aos já tradicionais acampamentos para venda de artesanatos encontrados em várias cidades do sul do Brasil 6 . O que ocorre na região litorânea é que a constituição dos grupos locais e a demarcação dos territórios precedem a definição de uma aldeia-mãe e aldeias-satélites (AQUINO, 2008, p. 32)7.

De outro modo, vemos que, ao avançar nessa perspectiva kaingang do Morro do Osso como uma aldeia-mãe, a fundação desta aldeia se orienta para a configuração de um "território xamânico" (ROSA, 2005) na região, bem como relaciona uma série de situações históricas relativamente recentes, aqui não detalhadas de forma factual, que ora se referem ao que eles denominam como "histórias dos antigos", ora remetem à primeira reivindicação territorial do povo Kaingang no litoral do Rio Grande do Sul, que extrapola a política local e assume um âmbito nacional (ver AQUINO, 2009). Isto é, conformando sua territorialidade a partir de um sítio com vestígios de ocupação ancestral ali existentes, enquanto objetos subjetivados como signos da relação com esses outros (cacos cerâmicos, mão de pilão, casa subterrânea e, entre outros, a pedra Pé de Deus, que possui uma cavidade com o formato de um pé, entendida por eles como resultado da atividade de antigos kujá, como dizem, pelo fato de assemelhar-se aos afiadores denominados na região como "panela de bugre"), os Kaingang reúnem as condições necessárias para estabelecer relações entre a natureza, sociedade e a sobrenatureza - domínios dos cosmos nos quais habitam diversos outros: mortos, Guarani, fóg (brancos), plantas, animais -, fundamentais para fundar

\footnotetext{
${ }^{6}$ Detive-me, naquele momento, de forma mais detalhada na análise da conquista da atual aldeia Lomba do Pinheiro no âmbito da prefeitura municipal de Porto Alegre e no posterior deslocamento ocasionado por um conflito de facções nessa aldeia, que teve como consequência a fundação de aldeia no Morro do Osso, sobrepondo a reivindicação de Terra Indígena tradicional a um parque natural pertencente ao município de Porto Alegre. De fato, em abril de 2004, os Kaingang passaram a reivindicar esta área como uma "terra antiga", que havia sido "perdida" para os brancos (fóg), devido à existência de um "cemitério indígena", e onde há um sítio arqueológico considerado pela arqueologia como pertencente à Tradição Guarani. Entretanto, antes deste momento de ocupação visando constituir uma aldeia, os Kaingang há muito coletavam matéria-prima para a confecção de artesanato no local, entrando muitas vezes em conflito com o guarda-parque, que proibia o manejo indígena das espécies utilizadas para este fim (tais como sementes, cipós e taquaras).

${ }^{7}$ De qualquer forma, as "conquistas", como dizem para escolas bilíngues, casas, centro culturais, posto de saúde, saneamento básico e demais benefícios que encontram no espaço aldeão, assemelham sua infraestrutura com aquelas das aldeias maiores e influenciam na configuração de alianças e na própria concepção do espaço que abrange o aglomerado.
}

Espaço Ameríndio, Porto Alegre, v. 8, n. 1, p. 109-134, jan./jun. 2014. 
uma aldeia e reivindicá-la como uma terra de ocupação tradicional.

Como veremos, durante os Encontros dos kujá temos uma configuração de relações entre aldeias que foi, em grande parte, formulada e conduzida pelas intenções das lideranças, articulando o parentesco e o xamanismo enquanto diferentes níveis de sociabilidade e de relação com o cosmos para reforçar o Morro do Osso como a aldeia potencialmente sede do aglomerado político-cerimonial na região litorânea. Para tanto, os Encontros possibilitaram atualizar um aspecto central para a fundação da aldeia do Morro do Osso em um sítio ancestral: a constituição de espaços rituais, já que a existência do "cemitério indígena" nesse local exigiu uma série de cerimônias, como, por exemplo, ritos de proteção do corpo e nominação, realizados com o fim de afastar os perigos que a alma dos mortos trazem para a aldeia8.

O I Encontro realizou-se em setembro de 2006, após o pa $i$ Kentanh percorrer algumas aldeias do planalto meridional e reunir recursos para trazer os kujá das respectivas aldeias (Nonoai e Iraí). Além de ser um Encontro de grande repercussão local, reunindo agentes do poder público, estudantes universitários, antropólogos, indigenistas; os Kaingang foram agraciados com uma quantia de 15 mil reais pelo Ministério da Cultura por sua realização, através do prêmio Ângelo Kretã. De forma mais ampla, tal como manifesto no acesso às políticas públicas para a própria realização do II, III e IV Encontros dos kujá, as atuações da liderança colocaram o xamanismo em evidência e reafirmaram alianças intra-aldeia e entre aldeias.

Infelizmente não pude acompanhar este I Encontro dos kujá, mas consegui participar do II, do III e do IV Encontros, também realizados no Morro do Osso, no final do mês de novembro, respectivamente em 2007, 2010 e 2012. Quando começaram esses Encontros, as atividades tinham como referência um palco com microfones, caixas de som, cadeiras, localizados no espaço público aldeão. Nas atividades realizadas no palco, coordenado pelos pa $i$, revezam-se os professores bilíngues, os agentes de saúde, os pëj (classe cerimonial, "rezadores") e os kujá.

\footnotetext{
${ }^{8}$ Segundo a interpretação da kujá Nimpre, devido às guerras de conquista, os ancestrais mortos no Morro do Osso não se beneficiaram de uma cerimônia mortuária necessária à partida para o nügme, permanecendo, pelo contrário, perambulando na aldeia, causando doenças e o afastamento da alma dos viventes (vënh kenhvég), convertendo estes últimos em vënh kuprïg (alma dos mortos).
}

Espaço Ameríndio, Porto Alegre, v. 8, n. 1, p. 109-134, jan./jun. 2014. 
O pátio e as casas ficam muito diferentes do que se observa no cotidiano. A quantidade de artefatos, arcos e flechas, lanças, cestarias, as roupas e cocares colorem a aldeia à medida que se espalham pelo pátio e adentram as casas. Observa-se, ainda, a importância das conversas informais, nas quais os Kaingang contam histórias e reavivam (ou refazem) contatos enfraquecidos ou interrompidos após deslocamentos sucessivos das "aldeias de origem", localizadas no planalto meridional, que culminaram com a fundação de aldeias na região litorânea. Fala-se das "comidas dos antigos" preparadas durante o Encontro, de que não viam há muitos anos os rituais que ali estão acontecendo, da "história dos animais" (ocorridas no tempo em que "os animais falavam"), de narrativas de antigos deslocamentos do planalto para a região litorânea, de acampamentos e aldeias antigas que os mais velhos ocuparam na região litorânea, etc.

Dentre as discussões e atividades previamente programadas, destacaram-se alguns eixos que se repetiram, com menor ou maior ênfase, nestes últimos Encontros. Um deles referia-se a políticas públicas, enfatizando as questões relativas à saúde, à educação bilíngue e, principalmente, à demarcação do Morro do Osso e de outras áreas indígenas. Outro eixo referia-se aos rituais, com os xamãs e os péj, de "queima de remédios" (vënh kagta pür) e de nominação. No II Encontro, as práticas xamânicas foram realizadas em determinados espaços, onde adquiriram um significado suplementar, desde que orientadas por um conteúdo que relaciona os diferentes domínios do cosmos à fundação de uma aldeia em um sítio considerado ancestral. No III e IV Encontro, com algumas exceções eventuais, os espaços rituais que foram consagrados durante o II Encontro, o qual, por isso, passo a narrar com mais detalhe, foram revisitados com a mesma finalidade ritual.

Os rituais xamânicos dividiram-se durante os três dias do II Encontro, entremeados pelas outras atividades citadas. No primeiro dia, os Kaingang realizaram o nén kãmï mü jé há ("vamos andar dentro da floresta"), para que uma fonte d'água (gój ror) fosse benzida (goj tu jé) pelos kujá. No segundo dia, foram até o "Pé de Deus" (tupë pën). Esta pedra foi considerada, desde as primeiras investidas da ocupação do Morro do Osso, um lugar onde teriam sido realizadas atividades mágicas no passado ancestral. Ali, os kujá iniciaram duas crianças no 
xamanismo e se reuniram aos pëj, abençoando-os para que estes rezassem (jé) para os mortos. No outro dia houve "queima de remédios" (venh kagta pür) no espaço público da aldeia.

O nén kãmï mü jé há reuniu os participantes do Encontro em uma caminhada dentro da mata para benzer a fonte d'água que fica em meio à floresta do Morro do Osso. Este ato tem como finalidade fazer com que uma fonte de água (gój ror) adquira capacidades curativas permanentes. Andaram em uma grande fila liderada pelos kujá, seguida pelo pa i mág do Morro do Osso, pelas mulheres e pelos guerreiros empunhando suas rogró pú (lanças).

Os "polícias", escolhidos na reunião que antecedeu o Encontro, ficaram à frente e atrás da fila, vigiando as trilhas que cortavam o caminho. Chegando à fonte d'água, todos se preparam para a cerimônia, postando-se em volta dos kujá. As lideranças discursaram em português. Cada um dos dois kujá que se "apresentaram" durante o Encontro retirou de suas sacolas "remédios do mato" (vënh kagta) com os quais realizaram o ritual. Pedro da Silva e sua esposa retiraram galhos e folhas de árvore e Jorge Garcia retirou uma casca de árvore. Ambos os kujá, após algumas palavras proferidas em um tom baixo, denominadas vï sï há (em que vï = falar; sï = pequeno, há = bom; a expressão traduz-se como "que ninguém pode ouvir", ou, ainda, "aquele que abençoa"), espalharam suas respectivas folhas e fios de lascas de casca, deixando a água com um cheiro impregnante. Os Kaingang dizem que, com este ato, os kujá conversavam ( vï sï há) com o espírito ou "guia" da planta e "abençoaram a água para curar". Ao fim do ritual, as lideranças discursaram, dizendo coisas como: "a água agora é boa, é sagrada, e pode ser utilizada pelos índios. Quando uma criança ficar doente as mães podem vir com uma bacia pegar a água e lavar as crianças".

Um dos kujá, Pedro da Silva, pegou as ervas molhadas na água e, recitando algumas palavras em tom baixo ( $v i ̈$ si há), passou as plantas sobre o ferimento do pa $i$ do Morro do Osso, visando curá-lo9. Depois, com os galhos de árvore, cujas folhas tinham sido molhadas na água

\footnotetext{
${ }^{9} \mathrm{O}$ pa $i$ Valdomiro, Xê, havia levado um tiro de um brigadiano (policial militar) em pleno Brique da Redenção, feira na qual os índios expõem seus artesanatos. Naquela ocasião, o cacique estava tentando garantir os direitos de uma mulher kaingang da Lomba do Pinheiro permanecer no lugar com sua "banca".
} 
benzida, abençoou os participantes. Os kujá disseram algumas palavras sobre o poder curativo daquela fonte, de que todos agora poderiam usufruir e, em seguida, os Kaingang passaram a lavar suas cabeças com a água. Ao fim desta sequência, os guerreiros, entre os homens adultos, segurando suas lanças se puseram a dançar em volta do kujá Jorge Garcia, que cantava "músicas espirituais" (cantando para a natureza, para as árvores, fontes de água, animais) no centro da roda. Assim encerram-se as atividades xamânicas programadas para o primeiro dia.

No segundo dia, houve a preparação de "comidas típicas" e foi executada a "Dança da Guerra" pelo grupo de guerreiros de Iraí, denominado $N o \tilde{g} g a^{10}$. Após a dança, a principal atividade foi a iniciação de dois kujá, uma criança do Morro do Osso e outra de São Leopoldo. A criança do Morro do Osso foi escolhida pelo kujá Pedro da Silva, que recebeu seus poderes da kujá com a qual Ga võg (pai do iniciante) "foi criado embaixo" (segundo o próprio Ga võg contou-me quando explicava um dos motivos da escolha). A iniciação da criança de São Leopoldo foi uma espécie de "pagamento", pois seu pai, Reféj, conforme me contou, pedira aos kujá que lavassem o menino com ervas para que ele melhorasse dos ataques de epilepsia, e esses lhe disseram que o fariam, mas que a criança teria que pagar curando as pessoas.

Esse evento também se inaugura com uma caminhada, mas diferente da anterior, pois não foi feita de modo coletivo. Dessa vez, os índios tinham como destino a pedra "Pé de Deus". Ao chegarem, um discurso "importante" foi proferido pelo kujá de Nonoai, Jorge Garcia. Ele subiu na pedra sob o "Pé de Deus" (estava rodeado por crianças e por todos os participantes do Encontro) e, em kaingang, começou:

Eu sou um velho (kofá) e não tenho por que mentir. Eu tive um sonho em que vinha caminhando e havia passado por uma pedra, via que estava cheio de crianças, mas não sabia onde era o lugar, e agora está acontecendo.

Prosseguiu referindo-se ao jykre kusá ("pensamento calmo"), um pensamento que vem do vento (frio) da floresta (no caso, do Morro do

\footnotetext{
${ }^{10}$ A sequencia da "Dança da Guerra" e a música que a acompanha são semelhantes àquelas executadas durante o processo de "conquista de terras" na região litorânea, descritas em minha dissertação de mestrado (AQUINO, 2008). Ali, mencionei que o grupo de dança de Iraí é considerado eficaz devido ao sucesso das várias demarcações de terras das quais participou.
} 
Osso, onde se localiza a fonte de água batizada no dia anterior) - este vento está em oposição ao vento quente, que traz preocupação ("tormento") -, exortando as lideranças e a audiência kaingang, que escutavam atentamente suas palavras, a manterem esse pensamento em suas ações.

Principiou-se então a cerimônia de iniciação xamânica. Ambos os kujá passaram "remédios do mato" na primeira criança, que estava em pé (filho de Ga vóg), o Jorge Garcia impôs a mão sobre sua cabeça. Pedro da Silva colocou um maço de folhas nas mãos do menino dizendo-lhe que deveria esfregar e depois soprar, para tirar o korég (espírito mal). Ele o fez. Enquanto assim procediam, proferiam palavras em tom baixo ( vï sï há), sem que a audiência escutasse. Veio a segunda criança (filho de Reféj), e o mesmo procedimento foi aplicado a ela, embora esta não esfregou e soprou os remédios que Ihe deram. Foi, entretanto, considerada iniciada - embora tenha sido sugerido por alguns que sua força xamânica tenderia a ser mais fraca que a do primeiro, ainda que também complementar.

Iniciou-se então a cerimônia de reza dos pëj, na qual eles cantaram/rezaram (jé). Os pëj, encostados uns aos outros, formavam uma linha - na qual também estava Rokã, vice-cacique do Morro do Osso. Esse canto/reza tinha como objetivo afastar os vënh kuprï, que estavam vagando no Morro do Osso desde as guerras com os brancos que os levaram a uma "morte sofrida". Enquanto os pëj rezavam, o kujá Jorge Garcia passava uma casca de árvore - apertando-a, por vezes - em suas testas e, fazendo a forma de cruz e gestos circulares e semicirculares e "falando baixo", descia pelo peito até a altura de seus umbigos. Fez o mesmo com as lideranças. Ao término das rezas, uma fila se formou para receber de Jorge Garcia esse mesmo procedimento. Nesse momento, o vice-cacique Rokã falou para toda audiência que esses kujá iniciados naquele momento seriam maior que os pa i mág, e que eles seriam respeitados por todos, e por todos "órgãos" (instituições dos brancos). Após o término da cerimônia de iniciação xamânica e da reza dos pëj, o vice-cacique Rokã disse em kaingang aos seus parentes: "amanhã irá se realizar o vënh kagta pür e o batismo".

A "queima de remédios" (vënh kagta pür) e o "batismo" foram realizados, significativamente, um dia após o "ritual aos mortos", no 
espaço público aldeão. Na entrada da aldeia foi acesa uma fogueira e os kujá singelamente foram colocando os remédios (plantas) para queimar. A fumaça adentrava a aldeia, enquanto os kujá preparavam, em um balde de plástico, uma infusão com cascas e folhas de árvores. Atrás dos kujá estava um pëj que, com um pequeno galho e um copo de plástico, fazia a tinta para a pintura corporal com carvão e água.

Escutei, nas caixas de som, Rokã dizer que o "batismo" e "a queima de remédios" iria começar. Uma fila enorme de crianças, mães com filhos nos colos, velhos, lideranças e jovens rapazes e moças, além dos brancos, se formou na entrada da aldeia. Os kujá davam nomes ou confirmavam os nomes e as metades das pessoas que, uma a uma, passavam por eles. Pedro da Silva lavava suas cabeças, enquanto Jorge Garcia dava-Ihes um copo com a infusão de ervas na água. As crianças que sabiam seus nomes passavam pelo mesmo tratamento dos adultos. Das que não o sabiam, os kujá perguntavam a alguém da fila (ou arredores) se tinham um nome; em caso negativo, os kujá perguntavam-Ihes sua ascendência (confirmavam com alguém a metade do pai) e davam-lhes um nome condizente. Os agentes de saúde, ao lado dos kujá, anotaram todos os nomes. Depois do banho de ervas, e de tomarem o copo de infusão, as crianças passavam por uma senhora kaingang que as pintava com ra téj (traços) e ra ror (círculos), conforme seu pertencimento às metades kamë e kanhru. Os Kaingang encerraram o evento com a "Dança da Guerra" realizada pelo grupo de dança de Iraí e do Morro do Osso.

O Encontro dos kujá, em grande parte conduzido pelas atuações das lideranças, sinaliza um contexto em que o kujá ocupa a cena público-cerimonial, como "raiz", jãre, do kanhgág há kar, para "transformar" o Morro do Osso em um lugar propício para o "crescimento da população". Dentre as técnicas rituais, os kujá recitam palavras, vï sï há, "que ninguém escuta" ou "que soam baixo", ou ainda, as palavras "[d]aquele que abençoa" por meio de um discurso que busca expressar valores sociais positivos, o que inclui a proteção da aldeia em relação aos mortos, com a queima de ervas (venh kagta pür), e o pertencimento às metades nos rituais de nominação ${ }^{1}$. Principalmente,

\footnotetext{
${ }^{11}$ No que se refere ao xamanismo, as relações intra e interaldeias na região litorânea, assim como as relações destas aldeias com aquelas do planalto, caracterizavam-se por uma marginalização dos kujá,
} 
devido à existência do cemitério indígena, "transformar" o Morro do Osso em uma aldeia pressupõe a utilização pelo kujá de técnicas rituais que fazem parte de um amplo campo de relações que envolvem a manutenção do coletivo kaingang, o que implica orientar sua capacidade de efetuar a mediação entre os diferentes domínios do cosmos para a proteção do corpo kaingang desse Outro específico, o morto.

Durante o Encontro, o exercício das práticas xamânicas insere-se na esfera público-cerimonial como referência na criação e organização de "pessoas fortes" e "guerreiras" (kanhgág tar hâ), já que os kujá, aí, atuam para expressar a qualidade de há ( $h a ́=$ bom), enquanto uma "qualidade que é reconhecida como melhor e deverá ser procurada" (WIESEMANN, 1960, p. 179; minha tradução), em oposição à korég (korég $=$ feio, mal), a qual é atribuída aos feiticeiros, denominados kujá korég. De forma mais ampla, os kujá articulam-se às ações dos pa i em benefício das formas sociais inauguradas em um tempo mítico, para estabelecerem alianças entre as metades exogâmicas kamë e kanhru.

Com isso, as lideranças legitimam sua atuação baseadas na "lei" aldeã, expressa no "falar duro" ( $v i ̈$ tar) - isto é, no respeito ( $t u$ há) entre os que pertencem a marcas 12 diferentes e na vergonha ( $\left.m \ddot{y}^{\prime} a\right)$ entre os que pertencem à mesma marca -, para constituir um aglomerado político-cerimonial, que é acionado para resolver conflitos internos, aconselhar casamentos, realizar cerimônias mortuárias e fazer política com as várias aldeias (envolvendo, em alguns contextos, também as aldeias do planalto) e, inclusive, com os brancos. De fato, antes dos Encontros dos kujá, essas aldeias na região litorânea já eram

\footnotetext{
pois, segundo meus interlocutores, as políticas dos órgãos indigenistas (SPI/FUNAI) e/ou a presença das igrejas nas Áreas Indígenas atuaram para cercear a prática xamânica. Assim, as relações entre liderança e xamanismo haviam se debilitado, por efeito dos termos em que se teve o contato com a sociedade nacional, e os kujá foram afastados de sua função na esfera público-cerimonial aldeã, qual seja, orientar as deliberações dos pa $i$ (quando não eram a mesma pessoa). Assim, mesmo quando estavam vinculados a famílias importantes politicamente, os kujá e outros especialistas (como as parteiras e os péj) atuavam apenas junto a seus parentes mais próximos e a quem os procurasse, ou eram acusados de feitiçaria e silenciavam sobre suas práticas xamânicas.

${ }^{12}$ Os Kaingang utilizam em seu português a palavra "marca", em geral, para se referirem às metades kamë e kanhru. Tal tradução, segundo dizem, deve-se a associação da "marca" com ra (escritura; sinal) da metade, assim como ra tej (traço) e ra ror (redondo, manchas e círculos) correspondem, respectivamente, a kamë e kanhru. Estas "marcas" ( $r$ ) são informadas, por exemplo, pelo padrão gráfico da pintura corporal de pessoas pertencentes a uma ou outra metade e na decoração da cestaria e outros artefatos (ver SILVA, 2001).
}

Espaço Ameríndio, Porto Alegre, v. 8, n. 1, p. 109-134, jan./jun. 2014. 
ALEXANDRE AQUINO - Ritual e xamanismo entre os Kaingang

intimamente conectadas entre si e com o planalto, por laços de parentesco e outras formas de relação - como as envolvidas na movimentação para coleta de material para a fabricação de artesanatos e de remédios (vënh kagta), ou na interação das lideranças que participam ativamente da vida política kaingang no cenário local, regional e nacional. Uma diferença, entretanto, é visível: no Encontro os Kaingang da região litorânea fortaleceram laços de parentesco e trocaram informações sobre caça, coleta, e outros elementos necessários para a atividade xamânica, não só em uma escala maior que em outros contextos, mas de uma forma pública e institucionalizada.

A partir dos Encontros que o Morro do Osso, sobretudo por ser uma área reivindicada como Terra Indígena - já que as demais aldeias da região litorânea são áreas que foram reivindicadas em âmbito local e adquiridas pelas prefeituras municipais -, afirma-se como polo político e cerimonial, conquistando assim uma importância política inédita na região, tanto em sua posição frente a outras aldeias no planalto, bem como enquanto aldeia-mãe em relação às demais aldeias-"satélites" do litoral. Em várias conversas com os participantes e observando algumas das atividades, percebi que essa questão estava, ora implícita ora explicitamente, colocada13. Durante o II Encontro, por exemplo, perguntei ao vice-cacique de Lajeado sobre o termo com que descrevem sua aldeia e sua resposta foi a seguinte: "ga sï porque é pequena (poucos hectares) e é uma aldeia nova; o Morro do Osso é uma ga mág porque é uma aldeia grande e uma terra antiga"14.

A relação entre aldeias também é expressa na distribuição das

\footnotetext{
${ }^{13}$ Em 2003, após seis anos de diálogo com a prefeitura de Porto Alegre, alguns Kaingang protagonizaram uma "luta" pela compra da Lomba do Pinheiro, localizada em "área rural-urbana" (Plano Diretor do município de Porto Alegre), cujo estatuto legal destina-se ao uso e não à posse dos indígenas. Segundo o documento que legalizava sua ocupação, os Kaingang deveriam respeitar certas características relacionadas a uma Área de Preservação Permanente. Entretanto, quando houve a primeira morte na aldeia, eles reivindicaram o direito de ter um cemitério no local e, após terem conseguido o amparo legal, sobrepondo assim à legislação ambiental, as lideranças enfatizam que se ocorrerem outras mortes na região os enterros seriam na Lomba do Pinheiro, o que expressa o caráter fluido na configuração desse aglomerado interaldeão.

${ }^{14}$ No dicionário bilíngue kaingang - português, de Ursula Wiesemann (2002), ga aparece como um substantivo que significa "terra". Vãre é um verbo intransitivo que tem o significado de "fazer acampamento". Ëmã, outro substantivo, significa "moradia", "habitação" (seu sinônimo, jamãa, seria um "substantivo dependente"). No que se refere às análises antropológicas, Tommasino (1995) foi quem mais se deteve sobre essas noções. Em sua análise, os termos vãre e ëmã são traduzidos, respectivamente, como "acampamento" (ou "abrigo provisório") e "aldeia". Estes termos podem, em determinados contextos, ser utilizados por eles de maneira mais ou menos intercambiável e, ao mesmo tempo, fornecem, cada um, diferentes maneiras de entender o pensamento kaingang (ver AQUINO, 2008).
}

Espaço Ameríndio, Porto Alegre, v. 8, n. 1, p. 109-134, jan./jun. 2014. 
famílias na atividade de preparação de "comidas típicas". Deixando de lado a complexidade da cozinha kaingang, que envolve homens e mulheres, enfatizo o modo como a relação entre as aldeias da região litorânea se manifesta explicitamente no arranjo dos "fogos". A distribuição das aldeias nos "fogos" era a seguinte: cada aldeia do planalto - Iraí (II e IV Encontro) e Nonoai (II, III e IV Encontro), Rio da Várzea (III Encontro), Votouro (III e IV Encontro), Inhacora (VI Encontro) tinha seu próprio "fogo", que se localizava próximo a cada uma das duas casas onde seus moradores ficaram hospedados; no II Encontro as aldeias de Lajeado e São Leopoldo fizeram um só "fogo", enquanto o Morro do Osso teve seu próprio "fogo" (talvez porque as mulheres estavam envolvidas nas tarefas da cozinha coletiva e os homens distribuídos em tarefas diversas, segurança, organização e limpeza do Encontro como um todo, a tarefa de preparação dos alimentos no "fogo" coube a uns poucos membros da comunidade). No III Encontro, entretanto, as lideranças do Morro do Osso perguntaram, no microfone, ao cacique de São Leopoldo, cuja terra de origem é Votouro, se ele se juntaria ao "fogo" desta última aldeia ou ao "fogo" do Morro do Osso, ele respondeu: "Morro ...". No IV Encontro cada uma destas aldeias, Morro do Osso, Lajeado e São Leopoldo, fizeram seus respectivos "fogos".

Esta característica da territorialidade voltada para a configuração de alianças na região litorânea relaciona-se com o Morro do Osso a partir de um horizonte cultural e histórico comum. Principalmente, consideram os vestígios do sítio ancestral (notadamente, o "cemitério indígena" e a pedra popularmente conhecida na região como "Pé de Deus", além de, entre outros, um buraco (ou casa) subterrâneo, o "abrigo indígena", e cacos cerâmicos) definidores do estatuto de tradicionalidade da ocupação do Morro do Osso, que foi sendo resolvido por estas práticas rituais que remetem a um conteúdo mítico, permitindo-os relacionar estes índices de ocupação ancestral, enquanto parte das "histórias dos antigos", à continuidade da aliança entre kamë e kanhru15. A forma da vida aldeã e a reivindicação do território ocupado

\footnotetext{
${ }^{15}$ Como venho argumentando, esta cosmovisão dualista incide nas narrativas sobre sítios arqueológicos na região litorânea, pois remete à forma de ocupação ancestral, notadamente as regras de etiqueta que orientam as relações entre as metades; ver adiante. Esta relação que os indígenas fazem entre cultura material e organização social e cosmológica foi analisada por Silva (2001): "Quanto ao nível gráfico, seguindo o nível morfológico do sistema de representações visuais, cabe ressaltar que os grafismos (kong-
} 
ALEXANDRE AQUINO - Ritual e xamanismo entre os Kaingang

como terra ancestral, consequentemente, os permite acessar as narrativas dos antepassados sobre a ocupação do litoral, em uma continuidade temporal que se materializa no tempo presente (üri) na relação entre metades e na atuação do pa'í e do kujá na esfera públicocerimonial, bem como na lógica de apropriação de poderes exteriores que orientam suas ações, enquanto estabelecem as mediações necessárias para a constituição do coletivo Kaingang.

\section{O "bem-viver" (kanhgág há kar) e o "bom-pensamento" (kanhgág jykre): aspectos da vida social kaingang}

Quando chegamos nas aldeias kaingang ouvimos de início que algumas pessoas são kamë e outras são kanhru e que os casamentos são prescritos entre as pessoas que pertencem a metades opostas. Além disso, o cosmos kanhgág está também dividido entre elementos que pertencem a uma ou outra das metades e o mito da criação do mundo trata da origem da divisão cósmica originária feita pelos gêmeos ancestrais, kamë e kanhru, que (re)construíram o mundo após o dilúvio (ver BORBA, 1908) e estão relacionados, respectivamente, ao sol e à lua. Como me contou o professor bilíngue Dorvalino Reféj Cardoso:

Sol era mais forte e deu um soco no olho de Lua e este ficou mais fraco. Isto aconteceu porque estes astros eram da mesma marca e por isso brigavam, depois que Lua ficou mais fraco, ele perguntou o que ele faria agora que não podia mais trabalhar pois não estava em suas plenas capacidades. Resolveram então que lua iluminaria a noite, enquanto Sol, o dia. Daí em diante Lua passou a ser de outra marca e nunca mais brigaram. Sol é contrário a Lua mas são complementares, Sol vem para destruir e Lua para trazer a vida. O sol queima as plantas e Lua traz o

gãr) presentes nos wõgfy (kre ou tufy), e pintados nos corpos e outros objetos, como flechas - ndo, nda -, arcos - uyi -, cabaças - run-ia -, mortalhas - kurã -, etc, e mesmo, os grafismos presentes na cultura material pré-histórica das ditas tradições locais planálticas (Taquara/Itararé/Casa de Pedra) do sul do Brasil, como painéis rupestres ou cerâmica arqueológica (nga ta kukrü), são sempre referidos e classificados por meus interlocutores Kaingang como téi ou ror.Téi e ror são os nomes das marcas (ra) grafismos (kong-gãr) que identificam, respectivamente, as metades Kamé e Kanhru-krë, percebidas como um sistema que organiza o universo Kaingang (...) O sistema de representações visuais Kaingang marca e acentua, nos rituais, o pertencimento de seus membros a uma das duas metades" (SILVA, 2001, p. 167173).

Espaço Ameríndio, Porto Alegre, v. 8, n. 1, p. 109-134, jan./jun. 2014. 
orvalho para as plantas...

Desse modo, a cosmologia kaingang concede um lugar central para o dualismo enquanto uma forma de classificação da sociedade, da natureza e da sobrenatureza. Ainda, em acordo com o mito, a pessoa kaingang deve agir em relação a uma pessoa de outra metade como Sol e Lua agem um com outro, isto é, "não podem brigar, mas casar". Isto porque o casamento exogâmico é, igualmente, fundado nas narrativas míticas. Conforme Borba (1908, p. 22), o mito de origem kaingang:

Cazaram primeiro os Cayrukrés com as filhas dos Camés, estes com a daquelles, e como ainda sobravam homens, cazaram-os com as filhas dos Caingangues.

Dahi vem que, Cayrukres, Camés e Caingangues são parentes e amigos (BORBA, 1908, p. 22).

Essa ideologia dualista, presente na norma de exogamia das metades patrilineares, é ensinada para as crianças desde a tenra infância. Contam-se "histórias do gufâ" (gufã, tempo mítico) para as crianças e jovens, que mostram como a divisão dualista do cosmos está intimamente relacionada às práticas sociais relativas ao casamento. Após o casamento, o casal deve comportar-se em acordo com a "lei" da aldeia, em termos da qual o "respeito" (tü hâ) e a "vergonha" (my'a) entre kanhkã e jamré estão articulados desde o plano da vida mais íntima, embasando as ações dos cônjuges em prover sua subsistência, saber receber parentes, manter a paz doméstica (não brigar, não ser violento um com o outro, mesmo dentro de casa), entre outras coisas, até o plano da vida aldeã e entre aldeias, na forma dos valores do "bemviver" (kanhgág há kar) e do "bom-pensamento" (kanhgág jykre), constitutivos dos coletivos kaingang. Assim, o pertencimento às metades, e a oposição entre relações com kanhkã (pessoa/s de "mesma marca [metade]") e jamré (pessoas de "outra marca [metade]") é relevante para a vida kaingang em todos os contextos, da família extensa e do grupo doméstico ao âmbito da aldeia e aglomerados.

$\mathrm{Na}$ conexão entre as esferas doméstica e esfera públicocerimonial encontramos a relação entre jamré (mas também entre kakrë, 
para sogro, e má, para sogra; em G+2 kakrë kofá e má kofâ)16 denominada em português como uma relação entre "cunhados", ou seja, pessoas que pertencem a "marcas" diferentes. Esta relação se diz entre "aqueles que tem um profundo respeito e um querer bem ao outro". Na esfera doméstica, os jamré "só faltam dar comida na boca um do outro" e "nunca falam duro [vï tar] um com o outro". Se alguém comete algum erro, deve ser punido pelo aconselhamento de alguém da "mesma marca", que pode "falar duro" para mostrar que aquele errou. Quando a questão se torna muito grave, torna-se algo a ser resolvido na esfera pública, onde se dá o "conselho" aldeão - instância jurídica kaingang também expresso por um conselheiro (jãvã fa) da "mesma marca". Nesse contexto, o seu parceiro, "se gostar muito, mas muito mesmo, de seu jamrê", diz que vai ser punido no seu lugar [ser preso, por exemplo]". Daí o "conselho" aldeão pode optar por não punir e apenas enfatizam que o jamré que "gosta muito dele, é uma pessoa inocente e vai pagar por um erro que não cometeu"(AQUINO, 2008, p. 113).

Entre kanhkã (parentes de "mesma marca"), ao contrário, os Kaingang dizem que não precisam agir com o mesmo respeito que agem com os jamré. Na esfera doméstica, a atitude que se espera entre kanhkã é de licenciosidade, pode-se dizer de um parente que ele está mal-vestido e, como eles dizem, "só faltam lhe arrancar a comida e bater nele". Na esfera pública, como informei acima, a "lei”, efetivamente aplicada pelo "conselho" aldeão, é expressa por um membro (um líder) da mesma metade do acusado do erro, que é quem estabelece os parâmetros da conversa como se vê na prerrogativa do "falar duro" ( $v i$ tar) com o parente. As lideranças da outra metade apoiam as decisões desse seu jamré, mas com grande cautela para não desrespeitar o jamré acusado - o que configura, mais propriamente, uma relação de evitação. A liderança da outra metade do acusado inicia sua opinião em um tom solene: "eu nem vou falar muito porque você é meu jamrê".

Nesse contexto, verifica-se que a "estrutura da comunidade" está fundada tanto na aliança estrutural entre kamë e kanhru krë, quanto nas relações de aliança efetivas que constituem e articulam grupos domésticos, famílias extensas e nucleares. Segundo Crépeau, estas duas

\footnotetext{
${ }^{16}$ A relação entre estes parentes preserva, em geral, as mesmas formalidades da relação entre metades. O termo para genro é jamré e nora jamré fi, em que fi = mulher; em G-1: jamré si e jamré fi si.
} 
dimensões podem ser visualizadas em termos espaciais e sociológicos, os quais remetem a uma questão clássica na literatura entre os demais povos Jê, qual seja, a distinção entre a esfera doméstica e a esfera público-cerimonial. O autor dialoga com estudos de Lévi-Strauss e do HCBP, associando o dualismo (diametral) à estrutura de metades e um princípio triádico à organização espacial. Ele percebe que a relação entre grupos e categorias sociais com o espaço pode tomar uma forma concêntrica na tríade in/plur/nietkuxã (casa/espaço limpo/floresta), como segue:

Em contextos formais, cada mito, ritual, e relação social são descritos ou atualizados como sendo principalmente diádico, usando o contraste das metades kaméveineky/kairu -votor, enquanto as relações espaciais são descritas com dois sistemas triádicos: horizontalmente, pela utilização dos domínios "casa, espaço limpo, floresta", discutido antes, ou verticalmente, pelo contraste "alto, médio, baixo" (CRÉPEAU, 2006, p. 11).

Aqui, assim interpreto o autor, é como se existisse uma espécie de alternância na qual a ênfase ora recai no dualismo e ora na tríade espacial, ora na esfera público-cerimonial - o "conselho", o casamento exogâmico, a terminologia de parentesco, etc -, e ora na esfera doméstica -, na sequência casa, espaço limpo, floresta, que são espaços nos quais se desenvolvem as atividades cotidianas. As conexões entre essas esferas são importantes na configuração dos rituais entre os Kaingang, pois as cerimônias que acompanhei, por exemplo, no Encontro dos kujá, iniciam-se nas casas, na floresta ou estão simbolicamente associadas a elas.

Rogerio Rosa (2005), seguindo a análise empreendida por Crépeau aprofunda a descrição das relações que os Kaingang estabelecem com o espaço "a partir do cruzamento das relações formais diádicas e espaciais triádicas", para adentrar na "topologia de domínios concretos e hierárquicos" da sociedade kaingang. Conforme o autor:

os Kaingang concebem o seu espaço a partir de três níveis sobrepostos, quais sejam: o nível subterrâneo ou embaixo da terra (por sua vez, formado pelo domínio "nügme"), o nível terra (constituído pelos domínios "casa", "espaço limpo" e "floresta virgem") e o nível 
ALEXANDRE AQUINO - Ritual e xamanismo entre os Kaingang

mundo do alto (concebido pelos domínios "céu" e "fãg kawã" ou "kaikã") (ROSA, 2005, p. 159).

A análise do autor ressalta aspectos históricos importantes do complexo xamânico kaingang, os quais foram observados no decorrer das transformações estruturais da sociedade kaingang nos últimos dois séculos, indicando as implicações das formas diádicas e triádicas de organização do espaço para a organização social, política e religiosa da vida aldeã, isto é, para as transformações do "território xamânico". Conforme o autor:

Assim como os Kaingang concebem que a metade kame engloba a metade kanhru, no plano cosmológico o domínio "floresta virgem" engloba a "casa" e o "espaço limpo"; por sua vez, no plano sociológico, a "casa" (contemporaneamente, a casa do chefe político, do cacique) engloba o "espaço limpo" e a "floresta". (...). Pensando a partir do território xamânico kaingang, vimos que o ritual do Kiki, o mais importante ritual do sistema kujà do xamanismo kaingang, era realizado na fronteira 'centro' do domínio "floresta virgem" do nível terra. Mas a partir do sistema caboclo, o mesmo ritual mudou para a fronteira 'praça da dança', vinculada ao domínio "casa" do chefe cerimonial de nome pã'í, principal organizador do Ritual do Kiki. Por sua vez, as festas de santos, principal atividade ritual vinculada ao sistema caboclo, eram organizadas pelo kujà ou curandor na fronteira chamada 'igrejinha de tabuinhas' e 'ramada' do 'espaço limpo' (...) Dessa forma pode-se concluir que o sistema caboclo consiste em uma ideologia xamânica formulada pelos Kaingang a partir das mudanças estruturais que se desdobraram na sua cosmologia a partir das transformações que se sucederam em seus territórios xamânicos particularmente, a derrubada das florestas e o início do declínio do domínio "floresta virgem" - com mais ênfase, a partir do século dezenove (ROSA, 2005, p. 255-272).

Schwingel (2001), em sua pesquisa sobre chefia e globalização em Nonoai, revela a complexidade da operação do sistema de metades na vida pública aldeã, por meio de uma etnografia do funcionamento das atuações da liderança e do "conselho" que evidencia um padrão de relações sociais que remetem ao mito de origem: 
ALEXANDRE AQUINO - Ritual e xamanismo entre os Kaingang

As narrativas míticas acima referidas, portanto, informam que através das metades clânicas estabelecese um vínculo histórico e cosmológico entre os Kaingang situados no contexto do üri [tempo presente] e seus ancestrais. Vínculo que conseqüentemente se apresenta como uma possível mediação nas relações que se estabelecem na organização política Kaingang nas situações históricas no decorrer dos tempos. Entre os Kaingang de Nonoai, percebe-se que a identificação com as metades clânicas assume uma certa relevância (SCHWINGEL, 2001, p. 41; grifos meus).

A etnografia do autor revela as várias dimensões da reciprocidade nas quais as autoridades estão imersas, pois elas envolvem as relações de oposição e complementaridade visualizadas entre líderes, os quais, justamente por serem "cunhados" que pertencem a metades opostas, devem respeito às suas respectivas ações. No "conselho" isto é realizado pelo emparelhamento entre lideranças de metades opostas na função de "aconselhar", segundo um padrão replicado, conformem dizem: "o capitão dá conselhos aos da sua "marca' e o coronel aos da sua". Schwingel informa:

Observa-se, pois, que a organização política Kaingang, no contexto atual, obedece a uma autoridade que trata das questões relativas ao conjunto da população Kaingang de sua aldeia, identificado na língua e cultura kaingang pelo termo pã 'î mág, sendo traduzido para a língua portuguesa geralmente pela denominação cacique. O pã 'ï mág, como o próprio termo já denota, significando grande líder, apresenta-se como a autoridade que se situa no centro de uma ordem política, sobrepondo-se a um conjunto de autoridades que atuam como seus "auxiliares", designadas pelo termo Kaingang pã'î sï - que significa "chefias menores". Entre os pã 'ï sï, entretanto, persiste igualmente uma ordem que sobrepõe uns a outros em termos de autoridade, que se apresenta na seguinte disposição: ti krëm ke ag, que significa "os que estão logo abaixo dele", isto é, que estão logo abaixo do cacique, sendo identificados na língua portuguesa pelos postos de coronel e major. Ambos são escolhidos pelo cacique, sob o critério de serem "pessoas de confiança". Esses, no entanto, são os únicos, além do cacique, autorizados a atuar sobre o conjunto da comunidade. Mas, enquanto que a função do coronel destina-se primordialmente para as relações com a

Espaço Ameríndio, Porto Alegre, v. 8, n. 1, p. 109-134, jan./jun. 2014. 
ALEXANDRE AQUINO - Ritual e xamanismo entre os Kaingang

sociedade não indígena, o major exerce suas funções mais precisamente junto a população kaingang em nível local, coordenando ações junto as autoridades já instituídas. Ainda em nível menor, logo abaixo do coronel e do major, encontram-se os capitães (...) A autoridade dos capitães, restringem-se a um espaço social especifico que são as aldeias locais, identificadas na língua e cultura kaingang como nïgja tavi [nig ja tavi] (...) O capitão é considerado a autoridade máxima do nïgja tavi. Todavia, junto ao capitão, verificam-se outras autoridades, denominados pã 'ï kosïr [kãsir], cuja tradução para o português aproxima-se da noção de "pequenas autoridades" ou os menores. Essas autoridades menores, por sua vez são escolhidas pelo próprio capitão, e estão sob suas "ordens". Dentre os pã 'î̀ kosir encontram-se os cargos de sargento, cabo e três a quatro polícias, que atuam em nível da aldeia local (...) juntamente com os capitães, em cada aldeia local, atuam também dois conselheiros, denominados jãvã fa. Fundamentados basicamente em valores considerados como sendo da "tradição dos antigos", esses conselheiros parecem estabelecer uma espécie de mediação entre os interesses e necessidades mais abrangentes relativos a sociabilidade kaingang (SCHWINGEL, 2001, p. 112-114; inserções minhas entre colchetes).

O "conselho" aldeão é a "lei" kaingang (uma tradução no português indígena das expressões kanhgág há kar, "viver bem", e do kanhgág jykré, "bom-pensamento"). O "conselho" visa, além das decisões políticas, principalmente, controlar o casamento exogâmico, ou seja, casar, separar, explicar as regras de convivência conjugal (fundada no respeito entre as metades) e as obrigações de cooperação nas atividades de subsistência. Os líderes dizem, por exemplo: se tiver ciúme, vão trabalhar juntos. Se as regras não forem cumpridas, torna-se necessário o uso das "cadeias", e tanto o homem como a mulher podem ser enviados para a "cadeia" da aldeia em que residem ou de uma outra, visando separar os cônjuges que casaram errado (entre pessoas da metade) ou a pessoa que agiu errado com seu cônjuge.

No caso dos rituais kaingang narrados no item acima, é importante enfatizar que eles são realizados para fazer-se kamë e kanhru krë, o que também ocorre na vida cotidiana, por exemplo, quando uma metade aconselha uma pessoa da mesma metade para que 
se tenha respeito por alguém da outra metade; mas, nos Encontros, de forma controlada pelos rituais, enfatiza-se a importância das atuações e os discursos do pa i e do kujá, como marcados pelos atributos tar. Como vimos na descrição dos Encontros dos kujá, a mediação do xamã kaingang opera como um modo de apropriação transespecífica das "diferenças" entre os vários domínios do cosmos, para beneficiar a sociedade, o que faz a partir do sistema de metades ${ }^{17}$. De fato, o kujá exerce a mediação por meio de um "animal guia”, o jagrë, responsável pela "força de suas palavras" (kujá tar há), força que, por sua vez, está, como dizem os Kaingang, na "raiz" (jãre) do kanhgág jykre (jykre = costume; a expressão pode ser traduzida, aproximadamente, por "bompensamento") e do kanhgág há kar ("bem-viver"). Nos Encontros os kujá atuam prevendo e prevenindo doenças e protegendo a aldeia com "queimas de remédios [ervas medicinais]" ( vënh kagta pür).

Outro aspecto importante da atuação dos kujá, nos rituais realizados durante os Encontros, é o "batismo" (nominação) das crianças kaingang. Por meio desse ato, os kujá acessam um acervo de nomes, que incorporam uma variedade de capacidades a serem transmitidas aos mais novos. Essas capacidades são ora concebidas como capacidades dos "antigos", agora no mundo dos mortos ${ }^{18}$, ora vistas como originárias da natureza, onde os kujá iriam buscar os nomes (através do animal guia), transferindo para os seus portadores as propriedades das plantas, dos animais, insetos, e pedras ${ }^{19}$. O ritual de nominação é uma forma de (re)conectar as pessoas ao gufã (tempo mítico) através da

\footnotetext{
17 Como diz Silva (2002, p. 196-197): "O kuiã Kaingang apresenta-se, então, como o elemento domesticador dessa força [da agressividade do "matão"], usada por ele para prevenir, proteger, curar e prever. Seu poder vem do "matão" (...) O kuiã, portanto, detém um poder oriundo de outros domínios do cosmos: só ele ousa e consegue domesticar essas forças. Daí vem seu prestigio e poder social (...) A cosmologia Kaingang compartilha das cosmologias amazônicas o fato de plantas e animais possuírem espírito (tom, conforme os kaingang) (...) [Nesse contexto] Seres e objetos interpenetram o mundo social, sob o domínio do kuiã, para benefício exclusivo da sociedade Kaingang. (...) Ele [o kujá] é encarado como personagem social única para estabelecer a intermediação entre mundos concebidos diferentemente, mas não separados radicalmente".

${ }^{18}$ Esse aspecto é enfatizado por Veiga, que verifica a importância do ritual do kiki ("culto aos mortos") na nominação. Ela diz: "os vivos recuperam os nomes que os mortos utilizavam possibilitando que o nome torne a ser dado a uma criança que receberá por herança todas as prerrogativas daquele nome, recuperando para a comunidade o papel desempenhado por aquele ancestral" (VEIGA, 2004, p. 281).

${ }^{19}$ Segundo os Kaingang, cada animal, planta, pedra, assim como a floresta, rios, cemitérios, tem seu ton (que traduzem por "dono" ou "guia", ou, ainda, kujá) com o qual o kujá "fala baixinho" (vï sï há ou, como eles traduzem, "aquele que abençoa") para que este permita a apropriação de seus poderes, com os quais realiza a cura e a nominação; do mesmo modo, o kujá possui a capacidade de relacionar-se com o ton de seu jagrë.
}

Espaço Ameríndio, Porto Alegre, v. 8, n. 1, p. 109-134, jan./jun. 2014. 
apropriação dessa qualidades pessoais de um antepassado, como também da apropriação de qualidades encontradas no mundo natural, pois geralmente as pessoas recebem os nomes de elementos naturais que pertencem à sua metade por nascimento (isto é, patrilinearmente). Vemos que a nominação, juntamente com o vënh kagta pür, são duas formas rituais recorrentes orientadas para a constituição do corpo individual e coletivo; pois a primeira garante o pertencimento de uma pessoa a uma das metades, quando o kujá, ao recorrer de um acervo, "cola" o nome, dando saúde e força ao nominado. A segunda, queimamse ervas em uma fogueira, onde crianças e adultos, andando em fila, passam ao lado e/ou por cima da "fumaça que sai do chão"20, permite aos Kaingang protegerem-se em relação a esse Outro que deixou de ser humano, o morto, afastando-o da sociedade dos vivos ${ }^{21}$.

O pa' í, por sua vez, não controla a força de suas palavras ( $p a^{\prime} i$ tar hâ) por meio de um guia animal, como acontece com o kujá (a não ser quando uma mesma pessoa acumula os dois estatutos). Mais especificamente, o "poder" do pa'i na sociedade kaingang manifesta-se em sua capacidade de reunir seus kanhkã (da "mesma marca") e jamré (de "outra marca") em um coletivo (kanhgág kar), ao estabelecer formas específicas de ritualizar a relação entre as metades, por meio da "lei" da aldeia (e/ou "conselho" aldeão), e motivar as pessoas a agir coletivamente a partir do respeito à exogamia de metades, ao kanhgág há kar (o "bem-viver") e ao kanhgág jykre (o "bom-pensamento"), isto é, a importância de viverem conforme as regras de etiqueta e arranjos institucionais relacionados aos gêmeos ancestrais, kamë e kanhru.

\footnotetext{
${ }^{20}$ Esses rituais são comumente realizados em várias aldeias kaingang. A prática de queima de ervas é realizada de acordo com um calendário ritual próprio a cada kujá e que está relacionado ao seu primeiro contato físico com o jagrë. Em algumas situações, incorporam outras datas que incluem em seu calendário de festas anuais, como o "dia do índio", em 19 de abril. Nessas ocasiões os Kaingang aproveitam para batizar seus filhos, mas a nominação não é uma prática necessariamente associada ao vënh kagta pür. Essa "queima de remédios" é também parte dos ritos funerários como àqueles de segundas exéquias denominados de "Sétimo Dia", o qual ocorre sete dias após o enterro, com o objetivo de afastar a alma do morto e enviá-la para o nügme. Não sei se os rituais citados incidem sobre a recuperação de nomes, mas é um tema que precisa ser mais explorado, já que o ritual do kiki foi abandonado a partir da década $60 \mathrm{em}$ praticamente todas as aldeias e retomado somente na aldeia de Xapecó em meados dos anos 90.

${ }^{21}$ Segundo a concepção nativa, quando a pessoa kaingang está viva, a alma (vënh kënhvég) encontra-se no corpo. Na morte, esta alma sai do corpo e torna-se vënh kuprïg, a alma do morto. O processo de saída da alma e sua transformação em vënh kuprïg podem ser revertidos pelo xamã, que vai buscar a alma vehn kenvég. Se isso não for feito a tempo, no entanto, a alma é perdida, e pode ficar vagando no mundo dos vivos, trazendo doenças para as pessoas, ou ir para o nügme (aldeia dos mortos), o que depende da realização dos ritos funerários adequados.
}

Espaço Ameríndio, Porto Alegre, v. 8, n. 1, p. 109-134, jan./jun. 2014. 
Vale ressaltar que esse aspecto da formação de coletivos e sua relação com posições políticas, como chefes e xamãs, observados à luz da dimensão ritual, remonta a um tema clássico do americanismo, que se refere aos processos de fabricação do corpo e da noção de pessoa, como aqueles envolvendo nomes, cantos e marcas. Nesse sentido, Stutzman propõe que "o tema da fabricação ritual de certos tipos de pessoas que detêm prestígio, que organizam ou mesmo contêm outras pessoas" (2009, p. 26) é um movimento de intensificação de relações, de amplificação da pessoa (magnificação), no qual "a gênese dessas pessoas não pode ser dissociada da gênese de coletivos":

Parece claro então que o ritual fundamenta de maneira
exemplar essa economia de prestigio: se, de um lado,
ele produz pessoas e, então, certos tipos magnificados
de pessoas, ele também possibilita a essas pessoas
magnificadas constituírem de algum modo os seus
coletivos. Parece ser também um ponto comum que
para ser "dono" de um lugar - de uma casa, de um
grupo local etc. - é necessário antes ter sido "dono" de
uma festa. E essa qualidade de ser "dono", essa
qualidade de maestria, não é de modo algum
dissociável do processo da liderança aqui iluminado
(STUTZMAN, 2009, p. 29).

Nesse sentido, a configuração de espaços rituais com o intuito de estabelecer uma aldeia num sítio considerado ancestral reúne, juntamente com aqueles locais localizados na aldeia e ao seu redor, especialmente o domínio da floresta, um aspecto central na busca do "território xamânico" kaingang na região, onde os kujá agenciam poderes por meio de um saber guiado (auxiliados por espíritos de guias animais, minerais e plantas) e possibilitam a penetração dos "poderes provenientes do "matão" para o beneficio da sociedade" (SILVA, 2002). Em diversos momentos, estas atividades conectam-se com a esfera doméstica e com a esfera público-cerimonial de tal modo que técnicas e mágicas atualizem formas sociocosmológicas originadas no tempo mítico (gufã) e/ou no tempo antigo (vãsy), por meio das quais os discursos e práticas do pa'í (chefe) e do kujá enfatizam a constituição do coletivo. Como vimos, nos Encontros, as imbricações entre esfera doméstica e esfera público-cerimonial são constituídas por vários processos que visam a manutenção física e espiritual de todos que 
compõem o coletivo. Mais especificamente, essas imbricações traduzem o processo de fabricação do corpo - do corpo individual e do corpo coletivo - "um corpo que se faz como corpo de parente" (COELHO DE SOUZA, 2001, p. 75).

De fato, muitas cerimônias que acompanhei iniciam-se na esfera doméstica e terminam na esfera pública, onde compartilham com o coletivo mais amplo o que faz dos parentes próximos um único corpo, mais propriamente trata-se do que Gordon (2006, p. 290) descreveu na sociedade xikrin em termos de "sentimentos-afetos", a partir dos quais podem fazer com os outros corresidentes e/ou grupos locais a comunidade como um todo. Nesse contexto, articulam as relações intra e interaldeãs, a partir dos espaços rituais, particularmente, dos "fogos" que, durante os Encontros, obedecem à mesma lógica encontrada na relação entre aldeias localizadas no planalto meridional (onde se encontram as "terras tradicionais" demarcadas dos Kaingang), bem como as relações entre aldeias da região litorânea, ao reunirem corresidentes, entre parentes próximos e distantes; estes grupos locais, por sua vez, interagem num coletivo mais amplo.

Por fim, cabe ressaltar mais uma vez que a constituição de um aglomerado político-cerimonial interaldeão na região litorânea, em grande parte conduzida pela atuação das lideranças e dos xamãs, deixam em aberto a definição de uma aldeia-mãe e aldeias-satélites, configurando uma territorialidade flexível, certamente, desde que as relações entre aldeias, ainda em constituição, estabelecem-se por meio de relações sociais, políticas e cerimoniais específicas. O que ocorre, durante os Encontros, é que as características que marcam a eleição de uma aldeia-mãe, ou seja, aquelas que fundamentam a constituição de certas aldeias como centros cerimoniais, com especialistas rituais, e centros políticos, com chefia, ocupada em resolver "as coisas de fora", permanecem. Esses níveis de sociabilidade envolvem ações das lideranças, como aquelas atribuídas a um pa i mág (literalmente, "grande líder"), pois articula forças e bens externos à comunidade em favor desta - o que contrasta com outras lideranças da mesma aldeia e de outras aldeias, pois trabalham dentro da comunidade, denominados de pa i sï (literalmente, "pequeno líder") -, e juntamente com o xamanismo e o parentesco atuam na formação do kanhgág kar, o 
coletivo kaingang, e este pode ser, em um dado momento, uma aldeia, noutro o aglomerado de aldeias da região litorânea e noutro, ainda, um conjunto que inclui estes últimos, assim como as aldeias do planalto, como ocorreu nos Encontros dos kujá.

\section{Referências bibliográficas}

AQUINO, Alexandre Magno. Ën Ga Vyg Ën Tóg ("Nós Conquistamos Nossa Terra"): Os Kaingang no Litoral do Rio Grande do Sul. 2008. 213 f. Dissertação (Mestrado em Antropologia Social) - PPGAS, UNB, Brasília, DF, [2008].

Mü jé ha ("Vamos"): a fundação de aldeias Kaingang no litoral do Rio Grande do Sul. Tellus, Campo Grande, v. 9, n. 17, p. 111-136, jun./dez, 2009.

BORBA, Telêmaco. Actualidade Indigena. Curitiba: Impressora Paraenense, 1908.

COELHO DE SOUZA, Marcela. Nós os vivos: "construção da pessoa" e "construção do parentesco" entre alguns grupos jê. Revista Brasileira de Ciências Sociais, São Paulo, v. 16, n. 46, p. 69-96, jun. 2001.

O traço e o círculo: o conceito de parentesco entre os Jê e seus antropólogos. 2002. 679 f. Tese (Doutorado em Antropologia Social) - PPGAS - MN, UFRJ, Rio de Janeiro, [2002].

DIAS, Jefferson. A tradição taquara e sua ligação com o índio kaingang . 2004. 230 f. Dissertação (Mestrado em História) - PPGH, UNISINOS, São Leopoldo, RS, [2004].

CRÉPEAU, Robert. Os Kamé vão sempre primeiro: dualismo social e reciprocidade entre os Kaingang. In: Anuário Antropológico 2005. Rio de Janeiro: Tempo Brasileiro, 2006. p. 9-33.

FERNANDES, Ricardo Cid. Uma contribuição da antropologia política para a análise do faccionalismo Kaingang. In: TOMMASINO, Kimiye; MOTA, Lúcio Tadeu; NOELLI, Francisco Silva (Org.). Novas contribuições aos estudos interdisciplinares dos Kaingang. Londrina: Eduel, 2004. p. 83-143.

GORDON, César. Economia Selvagem: ritual e mercadoria entre os índios XikrinMebêngôkre. São Paulo: Editora Unesp, 2006.

SCHWINGEL, Lúcio Roberto. Chefia kaingang num processo de relações interétnicas e de globalização: uma abordagem a partir da comunidade de Nonoai (norte do estado do Rio Grande do Sul). 2001. 264 f. Dissertação (Mestrado em Antropologia Social) - PPGAS UFRGS, Porto Alegre, RS, [2001]. 
ROSA, Rogério Reus Gonçalves. Os Kujà São Diferentes: Um Estudo Etnológico do Complexo Xamânico dos Kaingang da Terra Indígena Votouro. 2005. 416 f. Tese (Doutorado em Antropologia Social) - PPGAS, UFRGS, Porto Alegre, RS, [2005].

SILVA, Sérgio B. Etnoarqueologia dos grafismos "Kaingang": um modelo para a compreensão das sociedades Proto-Jê meridionais. 2001. 366 f. Tese (Doutorado em Antropologia Social) - PPGAS, USP, São Paulo, SP, [2001].

Dualismo e Cosmologia Kaingang: o xamã e o domínio da floresta. Horizontes Antropológicos, Porto Alegre, n. 18, p. 189-207, 2002.

STUTZMAN, Renato. De caraíbas a morubixabas: a ação política ameríndia e seus personagens. R@U: Revista de Antropologia Social dos Alunos da UFSCAR, São Carlos, v. 1, p. 16-45, 2009.

TOMMASINO, Kimiye. A história Kaingáng da Bacia do Tibagi: uma sociedade Jê meridional em movimento. 1995. 416 f. Tese (Doutorado em Antropologia Social) PPGAS, USP, São Paulo, SP, [1995].

VEIGA, Juracilda. Organização Social e cosmovisão Kaingang: ima introdução ao parentesco, casamento e nominação em uma sociedade Jê Meridional. 1994. 220 f. Dissertação (Mestrado em Antropologia) - Instituto de Filosofia e Ciências Humanas, Universidade Estadual de Campinas, Campinas, [1994].

Cosmologia Kaingang e suas práticas rituais. In. TOMMASINO, Kimiye; MOTA, Lúcio; NOELLI Francisco Silva (Org.). Novas contribuições aos estudos interdisciplinares dos Kaingang. Londrina: Eduel, 2004. p. 267-284.

WIESEMMAN, Ursula. Semantic categories of "good" and "bad" in relation to kaingang personal names. Revista do Museu Paulista, São Paulo, v. XII, p. 177-184, 1960.

Dicionário Bilíngüe Kaingang-Português. Curitiba: Editora Evangélica Esperança, 2002. 